\title{
Perspective
}

Expert insights on a timely policy issue

\section{Harnessing Private-Sector Innovation to Improve Health Insurance Exchanges}

\author{
Carole Roan Gresenz, Emily Hoch, Christine Eibner, Robert S. Rudin, Soeren Mattke
}

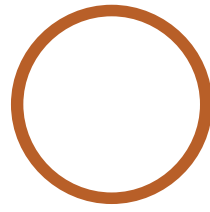
verhauling the individual health insurance marketincluding through the creation of health insurance exchanges - was a key component of the Patient Protection and Affordable Care Act's multidimensional approach to addressing the long-standing problem of the uninsured in the United States (Public Law 111-148, 2010). Despite succeeding in enrolling millions of Americans, the exchanges have confronted and still face several challenges, including poor consumer experience, high operational and development costs, and incomplete market penetration.

In this perspective, we consider a different model for the exchanges - a model that we term privately facilitated exchanges - which has the potential to address these challenges and deepen the Affordable Care Act's impact. In this model, the government retains control over sovereign exchange functions (such as regulation of insurers, eligibility determination, and transfer of subsidy payments to insurers) but allows the private sector to assume responsibility for more-peripheral exchange functions, such as developing and sustaining exchange websites (both the technical architecture and the software overlays that support plan comparison and enrollment). Although private-sector entities have already stepped into these exchange-related functions on a limited basis, privately facilitated exchanges could conceivably relieve the government of its responsibility for so-called front-end website operations and consumer decision-support functions entirely.

Although we do not offer a formal and conclusive assessment of the costs and benefits of this model, our analysis suggests that a shift to privately facilitated exchanges could improve consumer experience and, consequently, increase enrollment, and lower costs for state and federal governments. A move to such a model 
[W] consider a different model for the exchanges - a model that we term privately facilitated exchanges - which has the potential to address these challenges and deepen the Affordable Care Act's impact.

requires, nonetheless, managing its risks, such as reduced consumer protection, increased consumer confusion, and the possible lack of a viable revenue base for privately facilitated exchanges, especially in less populous states. On net, we believe that the benefits are large enough and the risks sufficiently manageable to seriously consider such a shift; we intend for this perspective to stimulate further discussion. In the rest of this paper, we provide background information and more detail on our assessment.

\section{A Brief Overview of the Affordable Care Act}

A primary objective of the Affordable Care Act was to address the long-standing problem of the uninsured. In 2011, approximately 50 million Americans_-roughly 16 percent of the population-had no health insurance coverage (Office of the Assistant Secretary for Planning and Evaluation, 2014). To improve coverage, Affordable Care Act provisions tackled fundamental issues relating to the availability and affordability of insurance. The law broadened the reach of public insurance, requiring most Americans to have health insurance or face a penalty (the so-called individual mandate), establishing health insurance exchanges, providing for a subsidy for the purchase of individual coverage, and putting in place a suite of insurance regulations.

\section{Public Insurance Expansion}

The Affordable Care Act expands public insurance by allowing states to extend Medicaid eligibility to anyone with an income below 138 percent of the federal poverty level (FPL) and offering federal subsidies to states to cover most of the costs associated with covering the newly eligible. As of January 2015, 29 states (plus the District of Columbia) adopted Medicaid expansion; six states were debating expansion; and 16 had elected not to expand (Paradise, 2015). Between October 2013 and December 2014, Medicaid and Children's Health Insurance Program (CHIP) enrollment increased by more than 10.7 million people in 49 states (Centers for Medicare and Medicaid Services, 2015). ${ }^{1}$

\section{Individual Mandate}

Additionally, the Affordable Care Act imposes a penalty on people who are not covered by insurance (with some exceptions). The penalty in 2014 was $\$ 95$ per adult and half that amount per child up to a maximum of $\$ 280$ per family or 1 percent of family income, whichever was greater. Penalties increase each year and, in 2015 (2016), are $\$ 325$ (\$695) for an adult and half that per child up to a maximum of $\$ 975(\$ 2,085)$ per family or 2 percent (2.5 percent) of income, whichever is greater. The law exempts people from the penalty who do not obtain coverage because they cannot afford it.

\footnotetext{
Connecticut and Maine did not report data.
} 


\section{Exchanges}

The Affordable Care Act requires the establishment of exchanges that allow people to purchase individual health insurance plans but provides states with latitude regarding the implementation of the exchange. ${ }^{2}$ In particular, a state may run its own exchange, participate in a federal exchange, or partner with the federal exchange (Dicken, 2013). In 2015, 13 states and the District of Columbia fully operated their own exchanges (called state-based marketplaces). Another three states performed all core functions of state-based exchanges but relied on the federal government's information technology platform to handle eligibility determination and enrollment (called federally supported state-based marketplaces). Among the 34 states that relied on the federal exchange, seven partnered with the federal government by performing plan management, consumer-assistance tasks, or other activities (called state partnership marketplaces). The remaining 27 states relied solely on the federal government for all exchange-related tasks (called federally facilitated marketplaces) (Dash, Monahan, and Lucia, 2013).

\section{Subsidy}

The Affordable Care Act provides a subsidy for people who purchase health insurance coverage through the exchanges if they have income between one and four times the FPL, are ineligible for Medicaid, and have no affordable employer offer. The federal government subsidizes premiums in the form of a tax credit. It caps premiums at 2 percent of income for those with incomes between

\footnotetext{
2 Our focus is on the individual exchanges, although the Affordable Care Act also established exchanges for small businesses.
}

\section{[A] state may run its own exchange, participate in a federal exchange, or partner with the federal exchange.}

100 and 133 percent of the FPL, at 3 to 4 percent of income for those with incomes between 133 and 150 percent of the FPL, and at an increasing percentage of income for higher income levels, up to 9.5 percent of income for those with incomes between 300 and 400 percent of the FPL. For families with incomes between 100 and 250 percent of the FPL, cost-sharing subsidies further limit out-of-pocket expenditures for care, although these subsidies apply only to those who purchase a silver-level plan (Andrews, 2013). Consumers can apply subsidies only to qualified health plans (QHPs) bought on the exchanges as described below. In King v. Burwell, the Supreme Court upheld the legality of the Affordable Care Act's subsidies in all states, regardless of whether the state operates its own exchange or relies on or partners with the federal exchange.

\section{Insurance Market Regulation}

The Affordable Care Act established a suite of regulations related to plans sold on the individual market, including the following:

- It requires that plans cover a minimum basket of specified essential health benefits (Center for Consumer Information and Insurance Oversight, undated).

- It establishes guaranteed issue and renewability.

- It removes preexisting-condition coverage exclusions.

- It prohibits insurers from using health status to rate premiums. 
- It allows insurers to vary premiums based only on age, region, family structure, and smoking status.

- It limits the amount of variation in premium by age (to a 3-to-1 maximum for people in the oldest versus youngest age bands, not including children) and by smoking status (1.5-to-1 for smokers versus nonsmokers).

- It requires regulatory review of annual health insurance premium increases.

The regulations also aim to increase transparency for consumers by requiring that plans sold through the individual market have standardized actuarial values (catastrophic, bronze, silver, gold, and platinum). Most of the Affordable Care Act's regulations apply to all individual market plans, whether those plans are sold on the exchanges or not (i.e., "off” exchange). However, all plans sold on the exchanges must be QHPs, a designation that requires adherence to additional requirements. QHP requirements include ensuring adequacy of provider networks, inclusion of essential community providers in the network, and accreditation with respect to quality measures. Although insurance providers can sell QHPs off the exchanges, the federal government makes subsidies available only for QHPs purchased on the exchanges. Figure 1 illustrates the universe of individual policy types.

\section{Exchange Functions}

The Affordable Care Act requires that exchanges perform a set of core functions, including eligibility and enrollment, plan management, and consumer assistance (Dicken, 2013; Barkakati and Wilshusen, 2014). Both the federal and state exchanges have been developed through public-private collaboration, primarily

\section{Figure 1: Individual Market Policies}

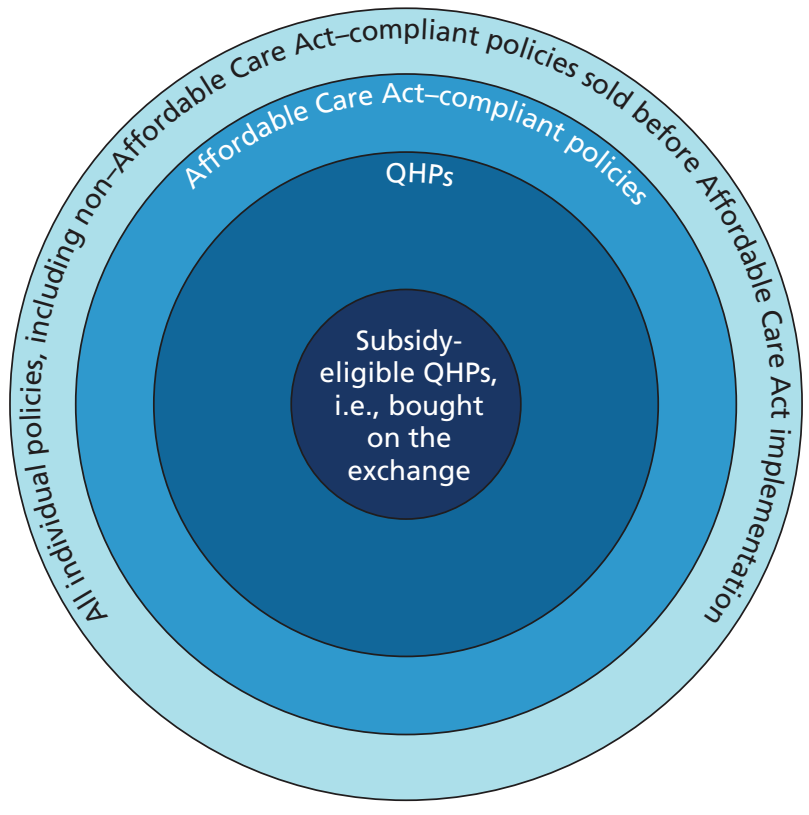

NOTE: The figure is illustrative only; ring sizes do not reflect distribution of individual policies by type. RAND PE152-1

in the form of government contracts to private entities to develop exchange components. Figure 2 depicts, at a high level, typical flows of information and the interactions among consumers, insurers, the exchanges, and the federal Data Services Hub (described below).

\section{Eligibility and Enrollment}

Exchanges share information with the federal Data Services Hub in real time to determine whether someone is eligible to purchase a plan on the exchange; enroll in Medicaid or CHIP; enroll in other 
government health care or health insurance programs; or receive a subsidy and, if so, its amount. The exchange must also facilitate enrollment in Medicaid or CHIP by transmitting information for eligible people to a state agency and must enroll them in the QHPs they have chosen (Dicken, 2013). The Data Services Hub supports eligibility determinations by accessing information from government agencies, such as the Social Security Administration, the Internal Revenue Service, and DHS, to confirm Social Security number, income, citizenship, and the like. The federal government

\section{Figure 2: Information Flows and Interactions Among Entities in Exchange Functions, Current State}

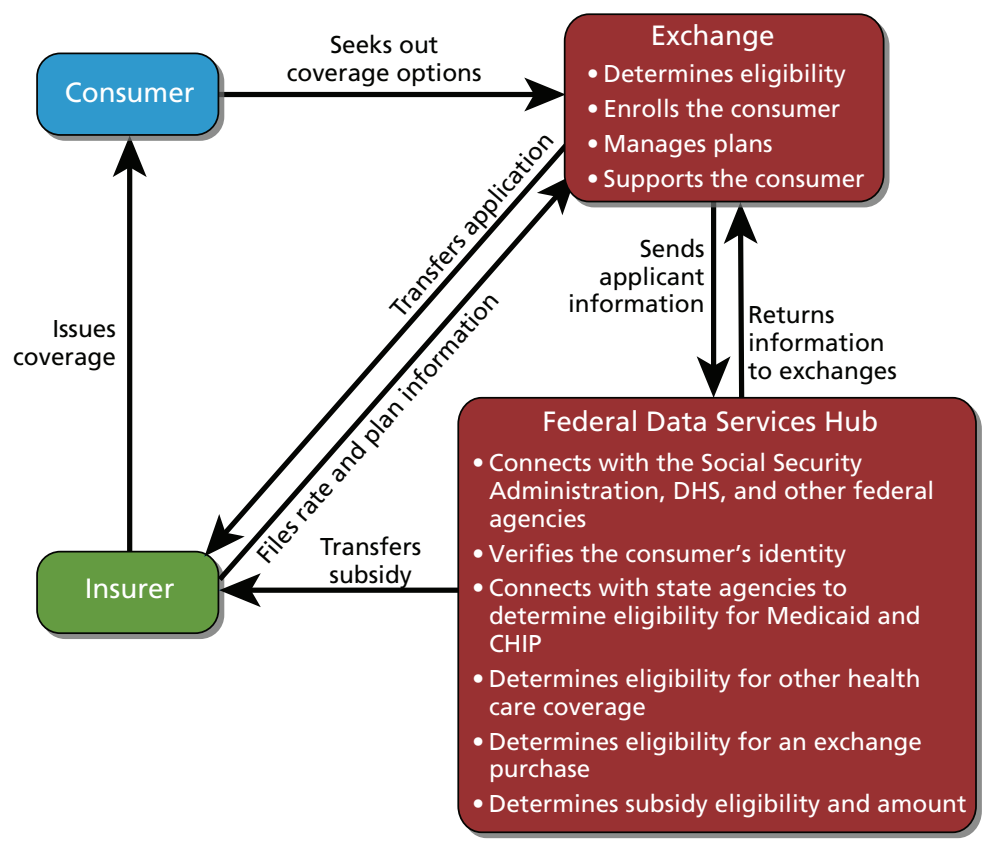

NOTE: DHS = U.S. Department of Homeland Security. RAND PE152-2 is responsible for making subsidy payments to issuers for enrollees in both state exchanges and the federal exchange.

\section{Plan Management}

Exchanges must have processes for insurers to apply to offer a health plan on the exchange, to determine whether a health plan meets QHP standards, and for ongoing review and oversight (Dash, Lucia, et al., 2013). ${ }^{3}$ The QHP application process is a critical and complex part of plan management because it ensures that offered policies meet the standards and may be subsidized. In short, the plan provider must submit a series of interlocking templates for each plan. The documentation requirements are considerably more complex than prior requirements of state regulators, and providers must compile the documentation in a short time frame between the release of the federal guidance documents and the QHP submission window.

\section{Consumer Assistance}

Consumer-assistance functions for exchanges include provision of a website, decision-support tools to enable comparison of available QHPs and the impact of any subsidy, a toll-free hotline and in-person assistance, a navigator program to provide impartial information about the exchanges and help people select plans, and

\footnotetext{
3 States that chose to operate their own exchanges had flexibility regarding various aspects of the exchanges, and one of the ways in which they varied was in terms of how they recruited or limited insurers participating in the exchanges and plans offered on the exchanges. Maryland, for example, explicitly required that certain insurers participate in the exchange; to limit the choices that consumers faced, the District of Columbia adopted policies to ensure that the exchange offered only substantially distinct plans.
} 
outreach activities (Fernandez and Mach, 2013). Decision support includes website functionality, such as filtering of plans based on selected features (e.g., actuarial value or so-called metal type), premium, deductible, and insurance company. Some exchanges provide quality information for plans (Dash, Lucia, et al., 2013).

\section{An Alternative Model of Public-Private Collaboration}

The exchanges were designed, developed, and created in a relatively short period; millions of people enrolled in health insurance coverage through the exchanges; most consumers shopping on the exchanges have had choices among issuers; and premiums on the exchanges have been lower than expected. By October 2014, 6.7 million people were signed up for health insurance coverage through the exchanges, and enrollment reached 11.7 million in 2015 (Office of the Assistant Secretary for Planning and Evaluation, 2014, 2015b). By December 26, 2014, 14 months after the exchanges went live, HealthCare.gov hosted more than 15 million unique visitors (by comparison, Pinterest took almost two years to reach that volume) (Constine, 2012). In 2014,

74 percent of consumers were able to choose from three or more issuers, and federal officials expect that percentage to rise to more than 90 percent in 2015 (Office of the Assistant Secretary for

Premium rates in 2014 were considerably
lower for exchange plans than for plans
offered in the individual market before
Affordable Care Act implementation.

Planning and Evaluation, 2015a). Premium rates in 2014 were considerably lower for exchange plans than for plans offered in the individual market before Affordable Care Act implementation (Skopec and Kronick, 2013), and most consumers had access to coverage costing less than $\$ 100$ in out-of-pocket (postsubsidy) premiums (Office of the Assistant Secretary for Planning and Evaluation, 2015a). Further, premium increases between 2014 and 2015 have been modest ( 2 percent for the second-lowest-cost, or silver, plans) (Office of the Assistant Secretary for Planning and Evaluation, 2015a).

Without diminishing these successes in expanding and improving the individual market, it is important to recognize room for improvement. Evidence points to the existence of a sizable untapped market of consumers who are eligible for but not enrolled in health plans, including young adults: Approximately 15 million Americans who were uninsured in 2014 were eligible to purchase coverage through the exchanges (Office of the Assistant Secretary for Planning and Evaluation, 2014). Further, young adults, in particular, continue to have relatively high uninsurance rates-24 percent of adults ages 26 to 34 remained uninsured as of the third quarter of 2014 (Levy, 2014). At the same time, the exchanges have faced criticism over the quality of the consumer experience and have experienced significant technical challenges and high development costs (Dicken, 2013; Baker et al., 2014; Wong et al., 2014b; Venkatesh, Hoehle, and Aljafari, 2014).

In light of these challenges, we consider a different model for running the exchanges - a model that we term privately facilitated exchanges - that offers the potential to address these challenges and deepen the impact of the Affordable Care Act. In particular, we discuss a model with a greater role for the private sector for 


\section{The advent of aggregators for auto insurance-such as Google's Compare and Insurance.com, which provide consumers with tools for comparison shopping and coverage sign-up-suggests that consumers are willing to use aggregator sites in the insurance market.}

exchange functions exclusive of those that are arguably sovereign and thus must remain under government control. These sovereign functions include regulatory oversight over the insurance market; eligibility determinations for purchasing coverage through an exchange, for a subsidy, and for Medicaid or CHIP; and transfer of subsidies to insurers. State regulators have to ensure that coverage products comply with state and federal law and that insurers are financially sound. For plans that are eligible for the subsidy, state and federal regulators must also certify their QHP designations. Eligibility determinations and subsidy transfers require the integration of sensitive data from government agencies. However, other exchange functions are arguably more peripheral_-including operation of exchange websites, development and implementation of decision-support tools, data collection and synthesis to inform consumers about choices, and plan enrollment and payment-and thus might be more amenable to leveraging private-sector forces to address some of the challenges the exchanges face.

\section{Data Aggregators in Other Industries}

In other industries, private-sector entities commonly perform these types of data-aggregation functions. Companies billing themselves as web aggregators, data aggregators, or simply aggregators are "entities that collect information from a wide range of sources, with or without prior arrangements, and add value through post aggregation services” (Madnick et al., 2000, p. 1). Aggregators have existed for more than a decade in a diverse range of industries, including travel, finance, and car insurance. Some of these services have attracted millions of users by providing usable interfaces to easily compare products. The popularity and voluntary nature of these aggregators suggest that customers find them valuable. In some markets, multiple aggregators compete with each other. Because they generally list the same products (suppliers have an interest in submitting their products wherever their potential customers would find them), aggregators compete with each other on user experience, user satisfaction, and decision-support functionality. The advent of aggregators for auto insurance-such as Google's Compare and Insurance.com, which provide consumers with tools for comparison shopping and coverage sign-upsuggests that consumers are willing to use aggregator sites in the insurance market.

Innovative web-based services indicate the potential kinds of improvements that health insurance aggregators can achieve. Some popular web-based companies offer a highly streamlined consumer experience (e.g., Amazon), help simplify complex processes (e.g., TurboTax), or allow for shopping with greater price and option transparency in decisionmaking (e.g., Kayak or Expedia). Although we recognize that health insurance could be inherently more complex than these services because of uncertainty about future 
health expenditures and specialized terminology, for example, there is likely still room for innovation (Arnold et al., 2012).

\section{Web-Based Entities in the Health Insurance Domain}

Data aggregators have, in fact, begun to inhabit the exchange space (Kuranda, 2013). Several websites, commonly called web-based entities, "scrape" and synthesize data from HealthCare.gov and state exchange websites to provide enhanced decision support (Center for Consumer Information and Insurance Oversight, 2014). One example is HealthSherpa (Wlodarz, 2014). Originally designed as an "overlay" to the federal exchange website to provide decision support but not enroll consumers (instead directing consumers to the exchange after they selected a plan), the website is now partnering with the U.S. Department of Health and Human Services to make the enrollment process smoother for consumers (Fung, 2014). HealthSherpa interacts with the exchanges to obtain plan data and with the Data Services Hub for eligibility and subsidy determinations and payment to issuers. Other examples of these services are eHealthInsurance Services, Picwell, and GoHealth.

Web-based entities interact not only with the public exchanges and the Data Services Hub but also with insurer databases. They can obtain real-time information on a plan's provider network and cost data for common services and procedures. Some facilitate side-by-side comparisons of providers that are part of the network or of different plan options and allow customized filtering of those options.

\section{Privately Facilitated Exchanges}

A logical extension of web-based entities is our envisioned model of the privately facilitated exchange - that is, an exchange that takes
The privately facilitated exchanges could conceivably relieve the government of its responsibility for front-end website and consumer decision-support functions entirely.

over nonsovereign functions. The privately facilitated exchanges could conceivably relieve the government of its responsibility for front-end website and consumer decision-support functions entirely. In other words, once a sufficient number of functioning and financially viable exchanges have emerged, state and federal governments could cease operating the front ends of their exchanges and provide only the back-end functions of the Data Services Hub and regulatory oversight.

Operationally, private-sector entities would need to coordinate their functions with those functions remaining under government control. Two potential models exist for interactions with the Data Services Hub. One would be fashioned after E-Verify, ${ }^{4}$ which allows businesses to determine the eligibility of potential employees to work in the United States. In this model (we call it E-Subsidy), each exchange would interface with the federal Data Services Hub to verify a consumer's ability to purchase on the exchange, determine the consumer's eligibility for Medicaid or CHIP, and verify the consumer's eligibility for subsidy and the amount of any subsidy.

\footnotetext{
4 Employers have the option to enroll in E-Verify and can submit data of applicants and employees for verification. The U.S. Citizenship and Immigration Services then compares the information with immigration and Social Security Administration data to determine eligibility to work.
} 
The other model would resemble the PayPal system, in which the consumer creates a single account that allows that consumer to make secure payments on numerous websites. If we translate this model to the exchange context, the consumer would create an account on a third-party private website that would hold pertinent information about that consumer's eligibility to purchase exchange coverage and the amount of any subsidy. Exchanges would allow consumers to link to these accounts and use them to authorize the transfer of their eligibility and subsidy information.

Independently, the transition to privately facilitated exchanges could also pave the way toward greater automation of plan-management functions. Currently, insurers have to submit detailed information about health plans they intend to offer on the exchanges through so-called QHP templates. Those templates are a set of linked spreadsheets into which insurers enter data, such as corporate information, medical, dental and pharmacy benefits, network, copayments, and premium rates. They serve a dual purpose: They constitute both a regulatory filing and a repository for plan information on the exchanges. This dual purpose creates an operational challenge because the regulatory nature of the templates necessitates that they be static-i.e., errors cannot be corrected or changes incorporated quickly-but requires resubmission and uploading of the corrected templates during specified service windows. In other words, even if regulators and the carrier are aware of an error, the consumer could continue to see incorrect information for weeks. Similarly, information on a health plan that is dynamic by its very nature, such as network providers and their ability to accept new patients, cannot be updated in a timely fashion.
Going forward, the exchanges could directly interface with insurers to access up-to-date plan information, such as prices, benefits, and provider networks, similar to what happens in the travel industry, in which companies make data on availability and prices available to aggregators. The government would maintain control over the QHP certification process and responsibility for regulatory oversight of insurers, but this change would decrease the complexity of the QHP template, which would be reduced to a regulatory filing, and improve the accuracy and timeliness of displayed plan information. Figure 3 illustrates the data flows for privately facilitated exchanges under the e-subsidy operating model.

\section{Figure 3: Information Flows and Interactions Among Entities in Exchange Functions, Proposed E-Subsidy Model}

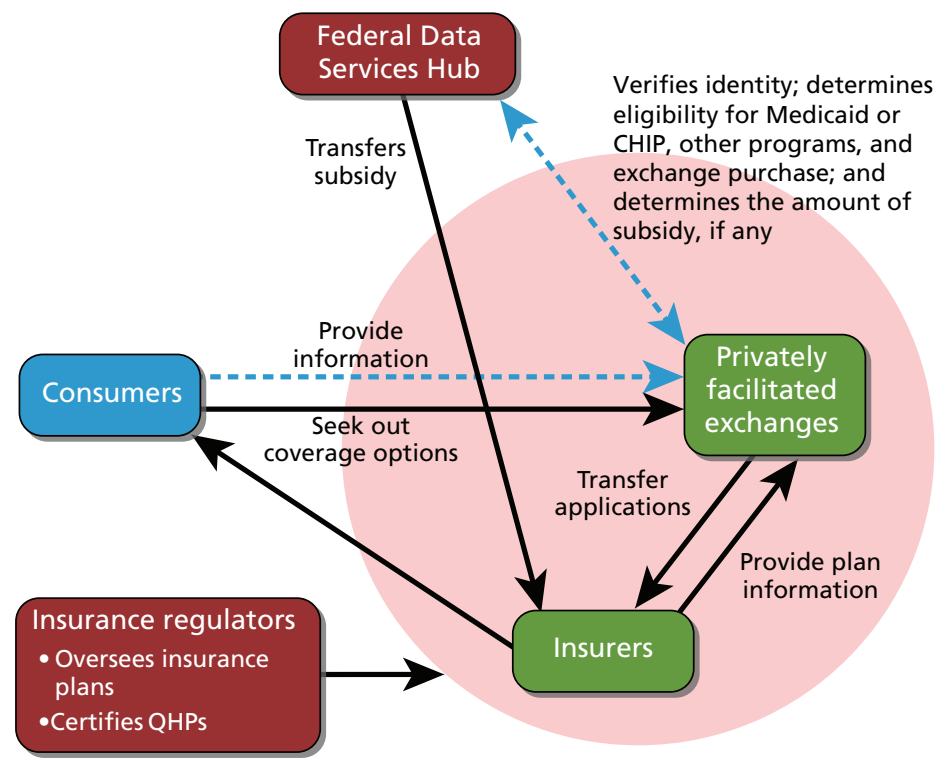

RAND PE152-3 
Greater convenience could also have the benefit of making the exchanges a more attractive destination for consumers who seek to obtain individual coverage but are not eligible for subsidies and a marketplace for insurance products beyond coverage that fulfills the requirements of the individual mandate, such as vision and dental insurance or supplemental coverage to cover copayments. In the next section, we consider the potential benefits and risks of a move toward privately facilitated exchanges.

\section{Potential Benefits and Risks}

We consider the potential advantages and challenges of moving exclusively to privately facilitated exchanges by assessing the model along four dimensions: (1) consumer experience, (2) choice, (3) consumer protection, and (4) cost and sustainability.

\section{Consumer Experience}

The quality of consumers' experiences with state and federal government exchanges — not only with decision support related to plan choice but also the entirety of consumers' interactions with the exchange-has been less than optimal. Technical issues were a major problem during the first open-enrollment period. During the 2014 rollout, site glitches delayed early users — multihour wait times, blank menus, and prompts and questions not relevant to their circumstances (Ornstein, 2013). Although the federal exchange was designed to provide real-time eligibility and enrollment for Medicaid and CHIP, some users had to wait for extended periods of time to learn whether they had been granted access and, at times, had to reapply on their state websites. The rollout team treated these performance issues as a priority, and such problems have been far less common for users in 2015 ("HealthCare.gov's
Tech Improvements Mean You Can Now Window Shop," 2014; "Meet the Press Transcript," 2014).

Decision support is a key element of the consumer experience and is critical for helping consumers select plans that will best serve them (Krughoff, Francis, and Ellis, 2012). Recommended best practices in terms of decision support include the following:

- providing an out-of-pocket cost calculator that enables consumers to estimate total annual spending, including both premium and out-of-pocket costs

- enabling sorting and filtering of plans to highlight best-fit plans and to organize options, including shortcuts to help consumers select plans quickly

- highlighting summary information about what matters most to consumers

- providing a directory to display health care providers participating in each plan (Pacific Business Group on Health, 2013).

Several studies suggest that the federal exchanges have fallen short in terms of decision support. A systematic assessment of the choice architecture of federal and state exchanges found robust sorting and filtering options but limited decision support (Baker et al., 2014). For example, none of the exchanges provided personalized total cost estimates (including premiums, subsidies, and out-of-pocket expenses); none followed recommended usability standards (Doulgerof, 2008); none provided the choice between long versus short paths to enrollment; and few had integrated provider information (Ornstein, 2013). Between the 2014 and 2015 open-enrollment periods, the choice architecture remained largely the same, although some aspects, such as sorting and filtering and quality information, improved (Ornstein, 2013). 
Other studies of federal and state exchanges confirmed deficiencies with respect to the consumer experience, including health insurance jargon that can be confusing for nonexperts, overly complex filters and sorting tools for cost and coverage preferences, and an overwhelming number of options to some.

Other studies of federal and state exchanges confirmed deficiencies with respect to the consumer experience, including health insurance jargon that can be confusing for nonexperts, overly complex filters and sorting tools for cost and coverage preferences, and an overwhelming number of options to some (Brownlee, 2014; Wong et al., 2014a, 2014b). Content organization, user experience, graphics, and navigation have been identified as key leverage points for improvement (Venkatesh, Hoehle, and Aljafari, 2014). An additional limitation has been the lack of a robust mobile application for the federal exchange, despite the fact that an estimated 25 percent of all visitors to the federal exchange arrived by mobile devices (Brownlee, 2014).

The government contracting process requires defining clear specifications for deliverables up front; competition for the work based on understanding of the task, capabilities, prior experience, and cost; and award based on best value to the government at the time of the decision. Changes to scope, deliverables, and awardees require complex contract modifications, which likely limited the ability to use industry best practices in software and website design.
The monopoly nature of the award might have limited the incentive to continuously improve the product.

Web-based entities have endeavored to offer a more streamlined consumer experience. About 110,000 consumers have used HealthSherpa, which suggests that consumers see added value in the web service, although some experts have suggested that available decision support still falls short by some standards (Bidgood, 2015; “3\%," 2015; Sprung, 2014). According to its 2014 U.S. Securities and Exchange Commission filings, eHealthInsurance Services serves more than 1 million members.

A greater reliance on private-sector entities for the front-end exchange functions could substantially improve consumer experience. As we pointed out, the planned and rigid nature of government procurement processes is not ideally compatible with the innovation and experimentation paradigms of modern web design that have spawned highly user-friendly websites in many e-commerce markets. Competition between privately facilitated exchanges would likely ensure innovation and product differentiation. Niche providers could emerge that focus on hard-to-reach segments, such as the young. Notably, private websites are not currently required to comply with certain government requirements, such as accessibility for visually impaired users (Kuranda, 2013). If private-sector entities fully assume these functions, the federal government would need to regulate to ensure accessibility for all consumers (Kuranda, 2013).

A better consumer experience could, in turn, help boost enrollment among people who remain uninsured but are eligible to purchase on an exchange. The complexity of the process does not deter all such people from purchasing — cost, for example, is another consideration - but the ease of exchange purchase is a 
contributing factor. Among people who remained uninsured in California after the implementation of the Affordable Care Act, 6 percent reported that problems with the application process were a barrier to coverage. Among the uninsured who attempted to get coverage (roughly one-third of the uninsured), the majority found shopping for coverage difficult, with more than two-thirds reporting problems comparing plans or understanding out-ofpocket and premium costs (DiJulio et al., 2014). Additionally, in a survey of adult U.S. Latinos, among the 29 percent who reported visiting an exchange website, 5.7 percent tried to enroll but had problems that prevented them from enrolling, and another 2.3 percent did not try to enroll because doing so was too complicated or confusing (Latino Decisions, 2015).

\section{Choice}

Functioning markets for individual coverage have developed in all states, and at least two insurers offer individual policies on the exchanges of every state. However, the number of insurers that offer exchange policies remains limited in the less populous states, as Figure 4 illustrates. More than half of the states have fewer than four carriers, and West Virginia has only two.

We have not found evidence that the limited number of competitors in many states restricts consumer choice in a meaningful fashion. However, it does expose less populous states to the risk of having no plans or no competing plans that sell individual policies on their exchanges if only one or two companies decide to leave the market or become insolvent, as was the case with Iowa's CoOportunity Health. That departure left some consumers with only one company offering plans on the exchange (CoOportunity Health, 2015; Masters, 2015). This risk of companies leaving the
Figure 4: Number of Insurers Operating on Each State's Exchange

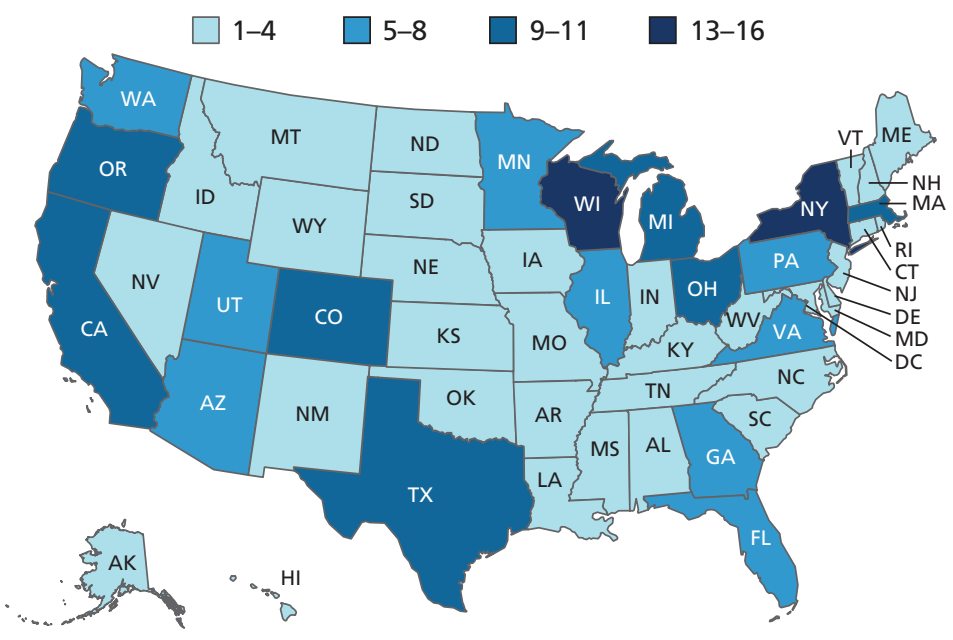

SOURCE: Henry J. Kaiser Family Foundation, 2015a.

RAND PE152-4

exchanges voluntarily is also real given the small size of some markets: Only about 12,000 and 18,000 individual policies were bought on Hawaii's and North Dakota's exchanges, respectively, for 2015 (Henry J. Kaiser Family Foundation, 2015b).

Through three changes to the cost-benefit trade-off, privately facilitated exchanges could attract additional insurers and increase the number of plan options that they make available. First,

companies would expect that improved consumer experience would attract more shoppers to the exchanges and makes actual purchases more likely (see earlier discussion) (Wong, 2014a; Latino Decisions, 2015). Second, the opportunity to market additional products, such as non-QHP plans and supplemental coverage, could entice insurers to participate in the exchanges, although insurers can 
already market those products through existing channels, such as brokers and their own websites. Third, an increase in insurer participation might follow if privately facilitated exchanges succeed in streamlining and automating plan-management functions-in particular, the QHP application process. This change would go well beyond the scope of the current web-based entities and would require collaboration between regulators, insurers, and private exchange operators.

\section{Consumer Protection}

The Affordable Care Act increased consumer protection in the individual market primarily through two mechanisms. The first was the creation of standardized and comprehensive policies with strict pricing regulation and guaranteed issue, and the second was the establishment of a unified exchange for subsidy-eligible plans, on which all available options are listed for comparison.

A shift to privately facilitated exchanges would not affect the first mechanism because regulations for individual market policies would still apply. However, competing exchanges might create confusion and uncertainty among consumers, in particular if exchanges may market QHPs along with non-QHP and other products, and offer only a subset of the available plans or plans of a single insurer.

Although it might be positive for competition and innovation, differentiation, if it confuses consumers, would undermine the law's intent to provide greater transparency and simplify decisionmaking. Even if insurer-specific or nonexhaustive websites include disclaimers about the information provided, some consumers might feel fatigue from the additional decision (choosing the type of exchange website from which to purchase insurance) beyond decisions about the QHP to purchase (Rice, 2013). Decision fatigue related to website choice could lead consumers to avoid the market and might differentially affect certain types of consumers, such as those with low health or financial literacy.

Further, consumers might not view the privately facilitated exchanges as being the same kind of honest broker as the government exchanges. Consumers might-legitimately-fear that filters, defaults, and other nudges will direct them toward certain plans that represent profit potential for the exchange provider or associated insurers, as opposed to representing the consumer's optimal choice. McWilliams points out that nudging is a form of agency and notes that the agent's interests might not necessarily align with the consumer's interests (McWilliams, 2013). Privately facilitated exchanges could also raise consumer concerns about data protection and privacy.

Measures to mitigate concerns about consumer protection include the following:

- maintenance of at least one exchange that lists all QHPs in a given market

\section{Although it might be positive for competition and innovation, differentiation, if it confuses consumers, would undermine the law's intent to provide greater transparency and simplify decisionmaking.}




\section{The existence of both short- and long-term revenue potential is essential if the government wishes to allow the private sector to fully provide the selected exchange functions}

- regulation to govern exchange transparency so that consumers know what range of plans is listed and which plans meet QHP criteria

- regulation to ensure that decision-support tools do not direct consumers to plans for profiteering purposes (e.g., kickbacks from certain insurers to exchanges for directing healthy people to its plans or from insurers to exchanges in response to prioritized direction to the insurer's plans). State insurance regulations address steerage by brokers, but the federal government would need to develop new regulatory guidance on the sale of insurance in this setting.

- strict regulation of data privacy and security to give consumers the same level of protection that they currently enjoy when enrolling through the federal or a state exchange

- enforcement of those rules with a cadre of skilled workers who can effectively monitor the exchanges and help avoid regulatory capture (wherein regulators act in the interest of privatesector entities that dominate the industry they are regulating instead of in the public interest) (Dal Bó, 2006).

Although effective monitoring and regulatory oversight could help alleviate these concerns in substance, private exchange websites would need to earn consumers' trust for potential gains in enrollment to be realized, and approaches to monitoring and regulation would need to be adapted to this context. Moreover, consumers would still need to have free access to navigators, as defined by the
Affordable Care Act, who provide unbiased advice on coverage options and support in completing the enrollment process.

\section{Cost and Sustainability}

The federal government launched HealthCare.gov with substantial investment of federal funds and staff resources. Although many experts have criticized the high development costs, those initial costs are sunk and should not influence decisions about the future exchange model. Instead, the appropriate comparison is between the costs to state and federal governments of directly providing front-end exchange services on the one hand and, on the other hand, monitoring the privately facilitated exchanges. The monitoring costs are probably considerably lower than the current operating budgets, and the potential savings thus could be substantial. For example, the federal contract to Accenture to support HealthCare.gov for the next five years is worth $\$ 563$ million (although not all of those costs are strictly associated with front-end services) (Accenture, 2014; Johnsrud, 2014). Looking ahead, we see that resources available for maintaining and improving the exchanges could be more limited, making more urgent the need to consider alternatives for increasing the affordability and sustainability of the exchanges. Although states relied on federal grants to develop their exchanges, the law requires that state exchanges be self-sustaining by 2015. Meanwhile, a change in administration 
from the presidential election could change funding priorities (Dash, Lucia, et al., 2013; Dash, Giovannelli, et al., 2014).5

The existence of both short- and long-term revenue potential is essential if the government wishes to allow the private sector to fully provide the selected exchange functions. The emergence of web-based entities in the context of health insurance and their longevity in other domains suggests that privately facilitated exchanges can be financially sustainable. Like travel websites, those exchanges could generate revenues from broker commissions, advertising, and listing fees for products other than QHPs. In the short term, the continued existence of state and federal exchanges while the privately facilitated exchange market incubates protects against instability in the market. Because the Affordable Care Act requires the existence of an exchange in each state, the health insurance industry might have to commit to maintain a consortium-funded exchange if no privately facilitated exchange appears sustainable in a given state.

\section{Summary}

The Affordable Care Act overhauled the individual health insurance market to help bring health coverage to the vast majority of Americans. A well-functioning and sustainable marketplace is integral to achieving the law's objective of reducing the number of uninsured. Several challenges the exchanges face suggest consideration of alternative models of public-private partnerships

\footnotetext{
5 Some states will use portions of existing premium taxes to help fund their exchanges; others could levy taxes on insurers in the individual and small-group markets; and some plan to use advertising revenue on exchange websites.
}

to support exchanges. These challenges include concerns about the consumer experience, costs of sustaining the exchanges, and uncertainty around the availability of resources for continuing operations, and the existence of a sizable untapped market of consumers who are eligible for but not enrolled in exchange plans, including young adults.

In this perspective, we discuss a model wherein the government retains control over core sovereign functions (regulation of insurers, eligibility determinations, and transfer of subsidy payments to insurers) but allows the private sector to assume responsibility for more-peripheral exchange functions, such as development and sustainment of the technical architecture for exchange websites and the software overlays that support plan comparison and enrollment.

Our analysis suggests that this shift could yield benefits in terms of improved consumer experience and, consequently, increased enrollment and lower costs for state and federal governments, although the shift would have to be gradual and closely monitored to ensure that viable, attractive, and trusted alternatives to the public exchanges emerge for all states. The main risks are reduced consumer protection, increased consumer confusion, and the lack of a viable revenue base for privately facilitated exchanges_-in particular, in less populous states. Overall, we believe that the benefits are large enough and the risks sufficiently manageable to seriously consider such a shift. We should qualify, however, that we intend for this perspective to stimulate the policy debate, and it does not offer a formal and conclusive assessment of costs and benefits. Efforts to monitor and rigorously evaluate privately facilitated exchanges already in operation will be important for informing the policy discussion going forward. 


\section{References}

“3\%," HealthSherpa, February 11, 2015. As of June 5, 2015:

http://blog.healthsherpa.com/3-percent

Accenture, "Accenture Awarded Five-Year Contract to Continue Successful HealthCare.gov Work," press release, December 29, 2014. As of June 5, 2015: http://newsroom.accenture.com/news/

accenture-awarded-five-year-contract-to-continue-successful-healthcare-gov-work. htm

Andrews, Michelle, "In Addition to Premium Credits, Health Law Offers Some Consumers Help Paying Deductibles and Co-Pays," Kaiser Health News, July 9, 2013. As of June 5, 2015:

http://khn.org/news/070913-michelle-andrews-on-cost-sharing-subsidies/

Arnold, Laurel, Jamie Brennan, Kristan Drzewiecki, Stuart Venzke, and Dave Walsh, White Paper: HIX Consumer Experience, Private Sector Technology Group, August 19, 2012. As of June 5, 2015:

http://www.pstg.org/newsletters/hix_consumer_experience_white_paper.pdf

Baker, Tom, Adrienne Beatty, Gabbie Nirenburg, and Janet Weiner, "Window Shopping on Healthcare.gov and the State-Based Marketplaces: More Consumer Support Is Needed," Philadelphia, Pa.: Leonard Davis Institute of Health Economics and Robert Wood Johnson Foundation, December 2014. As of June 5, 2015:

http://ldi.upenn.edu/uploads/media_items/

window-shopping-on-healthcare-gov-final.original.pdf

Barkakati, Nabajyoti, and Gregory C. Wilshusen, Healthcare.gov: Actions Needed to Address Weaknesses in Information Security and Privacy Controls, Washington,

D.C.: U.S. Government Accountability Office, GAO-14-730, September 2014. As of June 5, 2015:

http://www.gao.gov/products/GAO-14-730

Bidgood, Jess, "More Than One Way to Buy a Plan," New York Times, March 6, 2015. As of June 5, 2015:

http://www.nytimes.com/news/affordable-care-act/2014/03/06/

more-than-one-way-to-buy-a-plan/

Brownlee, John, “4 Things HealthCare.Gov 2.0 Gets Right (and 5 Things It Still Gets Wrong)," Fast Company, November 17, 2014. As of June 5, 2015: http://www.fastcodesign.com/3038669/

4-things-healthcaregov-20-get-right-and-5-things-it-still-gets-wrong
Center for Consumer Information and Insurance Oversight, "Essential Health Benefits Standards: Ensuring Quality, Affordable Coverage," undated. As of June 5, 2015:

http://www.cms.gov/CCIIO/Resources/Fact-Sheets-and-FAQs/ehb-2-20-2013. html

, "Health Insurance Marketplace Guidance: Role of Agents, Brokers, and Web-Brokers in Health Insurance Marketplaces,” Washington, D.C.: Centers for Medicare and Medicaid Services, U.S. Department of Health and Human Services, updated November 7, 2014. As of June 5, 2015: http://www.cms.gov/CCIIO/Programs-and-Initiatives/ Health-Insurance-Marketplaces/Downloads/ May_1_2013_CCIIO_AB_-Guidance_110414_508.pdf

Centers for Medicare and Medicaid Services, Medicaid and CHIP: December 2014 Monthly Applications, Eligibility Determinations and Enrollment Report, Baltimore, Md., February 23, 2015. As of June 5, 2015:

http://medicaid.gov/medicaid-chip-program-information/program-information/ downloads/december-2014-enrollment-report.pdf

Constine, Josh, "Pinterest Hits 10 Million U.S. Monthly Uniques Faster Than Any Standalone Site Ever-comScore," Tech Crunch, February 7, 2012. As of June 5, 2015:

http://techcrunch.com/2012/02/07/pinterest-monthly-uniques/

CoOportunity Health, "Notice of Liquidation for CoOportunity Health," February 28, 2015. As of June 5, 2015:

http://www.cooportunityhealth.com/

Dal Bó, Ernesto, "Regulatory Capture: A Review," Oxford Review of Economic Policy, Vol. 22, No. 2, Summer 2006, pp. 203-225.

Dash, Sarah J., Justin Giovannelli, Kevin Lucia, and Sean Miskell, "State Marketplace Approaches to Financing and Sustainability," Commonwealth Fund, November 6, 2014. As of June 5, 2015: http://www.commonwealthfund.org/publications/blog/2014/nov/ state-marketplace-approaches-to-financing-and-sustainability

Dash, Sarah J., Kevin Lucia, Katie Keith, and Christine Monahan, "Implementing the Affordable Care Act: Key Design Decisions for State-Based Exchanges," Commonwealth Fund, July 2013. As of June 5, 2015: http://www.commonwealthfund.org/publications/fund-reports/2013/jul/ design-decisions-for-exchanges 
Dash, Sarah J., Christine Monahan, and Kevin Lucia, "Health Policy Brief: Health Insurance Exchanges and State Decisions," Health Affairs, July 18, 2013. As of June 5, 2015:

http://healthaffairs.org/healthpolicybriefs/brief_pdfs/healthpolicybrief_96.pdf

Dicken, John E., Patient Protection and Affordable Care Act: Status of CMS Efforts to Establish Federally Facilitated Health Insurance Exchanges, Washington, D.C.: U.S. Government Accountability Office, GAO-13-601, June 2013. As of June 5, 2015:

http://www.gao.gov/products/GAO-13-601

DiJulio, Bianca, Jamie Firth, Larry Levitt, Gary Claxton, Rachel Garfield, and Mollyann Brodie, "Where Are California's Uninsured Now? Wave 2 of the Kaiser Family Foundation California Longitudinal Panel Survey," Henry J. Kaiser Family Foundation, July 30, 2014. As of June 5, 2015:

http://kff.org/health-reform/report/where-are-californias-uninsured-now-wave-2of-the-kaiser-family-foundation-california-longitudinal-panel-survey/

Doulgerof, Ivana, "Usability Glossary," in How to Improve the Usability of Our Websites: Main Findings and Conclusions from the Seminar Organised by the Management Organisation Unit, Greece, briefing to the Inform network of the European Commission, Brussels, November 27, 2008. As of June 23, 2015: http://ec.europa.eu/regional_policy/archive/country/commu/ docevent/26112008/5_doulgerof_glossary.pdf

Fernandez, Bernadette, and Annie L. Mach, Health Insurance Exchanges Under the Patient Protection and Affordable Care Act (ACA), Washington, D.C.:

Congressional Research Service, R42663, January 31, 2013. As of June 5, 2015: https://www.fas.org/sgp/crs/misc/R42663.pdf

Fung, Brian, "Signing Up for Obamacare Could Someday Take as Little as 10 Minutes," Washington Post, February 26, 2014. As of June 5, 2015: http://www.washingtonpost.com/blogs/the-switch/wp/2014/02/26/ signing-up-for-obamacare-could-someday-take-as-little-as-10-minutes/

"HealthCare.gov's Tech Improvements Mean You Can Now Window Shop," All Tech Considered, November 10, 2014. As of June 5, 2015:

http://www.npr.org/templates/transcript/transcript.php?storyId=363052856

Henry J. Kaiser Family Foundation, "Number of Issuers Participating in the Individual Health Insurance Marketplaces,” c. 2015a. As of June 5, 2015: http://kff.org/other/state-indicator/ number-of-issuers-participating-in-the-individual-health-insurance-marketplace/
"Marketplace Enrollment as a Share of the Potential Marketplace Population," March 31, 2015b. As of June 5, 2015: http://kff.org/health-reform/state-indicator/ marketplace-enrollment-as-a-share-of-the-potential-marketplace-population-2015/

Johnsrud, Sue, 2014-15 Covered California Budget, Covered California, c. 2014. As of June 5, 2015:

http://hbex.coveredca.com/financial-reports/PDFs/2014Budget.pdf

King v. Burwell, 576 U.S. __ June 25, 2015. As of June 29, 2015:

http://www.supremecourt.gov/opinions/14pdf/14-114_qol1.pdf

Krughoff, Robert, Walton Francis, and Robert Ellis, "Helping Consumers Choose Health Plans in Exchanges: Best Practice Recommendations," Health Affairs Blog, February 29, 2012. As of June 5, 2015:

http://healthaffairs.org/blog/2012/02/29/helping-consumers-choose-health-plansin-exchanges-best-practice-recommendations/

Kuranda, Sarah, "HealthCare.Gov v2.0: Software Developers Create Site to Trump Obamacare Site Woes," CRN, November 18, 2013. As of June 5, 2015: http://www.crn.com/news/channel-programs/240164064/healthcare-gov-v2-0software-developers-create-site-to-trump-obamacare-site-woes.htm

Latino Decisions, Topline Results: Latino National Health Survey, Robert Wood Johnson Foundation Center for Health Policy at the University of New Mexico, March 24, 2015. As of June 5, 2015:

http://www.latinodecisions.com/files/1214/2707/3700/

UNM_RWJF_Center_Toplines_Posted.pdf

Levy, Jenna, “In U.S., Uninsured Rate Holds at 13.4\%,” Gallup, October 8, 2014. As of June 5, 2015:

http://www.gallup.com/poll/178100/uninsured-rate-holds.aspx

Madnick, Stuart, Michael Siegel, Mary Alice Frontini, Saraubh Khemka, Steven Chan, and Howard Pan, Surviving and Thriving in the New World of Web Aggregators, unpublished paper presented at the Society for Information Management Workshop, Brisbane, Australia, December 2000.

Masters, Clay, "Health Insurance Startup Collapses in Iowa," National Public Radio, January 14, 2015. As of June 5, 2015:

http:/www.npr.org/sections/health-shots/2015/01/14/376792564/ health-insurance-startup-collapses-in-iowa

McWilliams, J. Michael, "Information Transparency for Health Care Consumers: Clear, but Effective?" Journal of General Internal Medicine, Vol. 28, No. 11, November 2013, pp. 1387-1388. 
“Meet the Press Transcript: November 16, 2014," NBC News, November 16, 2014. As of June 5, 2015:

http://www.nbcnews.com/meet-the-press/

meet-press-transcript-november-16-2014-n249601

Office of the Assistant Secretary for Planning and Evaluation, "How Many Individuals Might Have Marketplace Coverage After the 2015 Open Enrollment Period?" U.S. Department of Health and Human Services, issue brief,

November 10, 2014. As of June 5, 2015:

http://aspe.hhs.gov/health/reports/2014/Targets/ib_Targets.pdf

Health Plan Choice and Premiums in the 2015 Health Insurance

Marketplace, U.S. Department of Health and Human Services, updated January 8, 2015a. As of June 5, 2015:

http://aspe.hhs.gov/health/reports/2015/premiumreport/healthpremium2015.pdf

- Health Insurance Marketplaces 2015 Open Enrollment Period: March Enrollment Report, U.S. Department of Health and Human Services, March 10, 2015b. As of June 5, 2015:

http://aspe.hhs.gov/health/reports/2015/MarketPlaceEnrollment/Mar2015/

ib_2015mar_enrollment.pdf

Ornstein, Charles, "Please Wait": New-and-Improved HealthCare.gov Has Same Old Problems, ProPublica, December 2, 2013. As of June 5, 2015:

http://www.propublica.org/article/

new-and-improved-healthcare-dot-gov-has-same-old-problems

Pacific Business Group on Health, "Top 5 Rules for Decision Support, and

Strategies to Bridge the Gaps," issue brief, 2013. As of June 5, 2015:

http://www.pbgh.org/storage/documents/

PBGH_PlanChoiceBrief_Top5Rules_022113.pdf

Paradise, Julia, Medicaid Moving Forward, Kaiser Commission on Medicaid and the Uninsured, March 9, 2015. As of June 5, 2015:

http://kff.org/health-reform/issue-brief/medicaid-moving-forward/
Public Law 111-148, Patient Protection and Affordable Care Act, March 23, 2010. As of June 5, 2015:

http://www.gpo.gov/fdsys/granule/PLAW-111publ148/PLAW-111publ148/ content-detail.html

Rice, Thomas, "The Behavioral Economics of Health and Health Care," Annual Review of Public Health, Vol. 34, 2013, pp. 431-447.

Skopec, Laura, and Richard Kronick, Market Competition Works: Proposed Silver Premiums in the 2014 Individual Market Are Substantially Lower Than Expected,

Washington, D.C.: Office of the Assistant Secretary for Planning and Evaluation, U.S. Department of Health and Human Services, updated August 9, 2013. As of June 5, 2015:

http://aspe.hhs.gov/health/reports/2013/MarketCompetitionPremiums/ ib_premiums_update.cfm

Sprung, Andrew, "How to Reboot Healthcare.gov," New Republic, September 17, 2014. As of June 5, 2015:

http://www.newrepublic.com/article/119474/

government-can-revive-obamacare-site-healthcaregov

Venkatesh, Viswanath, Hartmut Hoehle, and Ruba Aljafari, "A Usability Evaluation of the Obamacare Website," Government Information Quarterly, Vol. 31, No. 4, October 2014, pp. 669-680.

Wlodarz, Derrick, "Healthcare.gov: How Washington's IT Project Leviathan Failed Us, and Here's How We Fix a Broken System," BetaNews, May 5, 2014

Wong, Charlene A., David A. Asch, Cjloe M. Vinoya, Carol A. Ford, Tom Baker, Robert Town, and Raina M. Merchant, "The Experience of Young Adults on HealthCare.gov," Annals of Internal Medicine, letter, online-first version, July 8, 2014a. As of June 5, 2015:

http://di.upenn.edu/uploads/media_items/

the-experience-of-young-adults-on-healthcare-gov-suggestions-for-improvement. original.pdf

, "The Experience of Young Adults on HealthCare.gov: Suggestions for Improvement," Annals of Internal Medicine, Vol. 161, No. 3, 2014b, pp. 231-232. 


\section{Acknowledgments}

The research underlying this paper was sponsored by Aetna, Inc., and conducted in RAND Health Advisory Services, the consulting practice of RAND Health. The authors would like to thank Justin Giovannelli and Chapin White for their thorough review and instructive feedback. Special thanks also to Patrick Orr for helping us with figures, references, and copyedits. A profile of RAND Health Advisory Services, its capabilities and publications, and ordering information can be found at www.rand.org/rhas.

\section{About the Authors}

Carole Roan Gresenz is a senior economist and director of the Economics, Sociology, and Statistics research department. She holds a Ph.D. in economics from Brown University and a B.A. in economics from Loyola University Maryland.

Emily Hoch is manager of RAND Health Advisory Services, the consulting practice of RAND Health. She received her M.Sc. from the London School of Hygiene and Tropical Medicine and B.A. from the University of Wisconsin-Madison.

Christine Eibner is a senior economist at RAND. She earned her bachelor's degree in English and economics from the College of William and Mary and her doctorate in economics from the University of Maryland, College Park.

Robert S. Rudin is an information scientist at RAND. He holds a Ph.D. in technology, management, and policy at the Massachusetts Institute of Technology.

Soeren Mattke is a senior scientist and the managing director of RAND Health Advisory Services, RAND Health's consulting practice. He received his M.D. from the University of Munich and his M.P.H. and D.Sc. from the Harvard School of Public Health.

\section{Limited Print and Electronic Distribution Rights}

This document and trademark(s) contained herein are protected by law. This representation of RAND intellectual property is provided for noncommercial use only. Unauthorized posting of this publication online is prohibited. Permission is given to duplicate this document for personal use only, as long as it is unaltered and complete. Permission is required from RAND to reproduce, or reuse in another form, any of our research documents for commercial use. For information on reprint and linking permissions, please visit www.rand.org/pubs/permissions.html.

The RAND Corporation is a research organization that develops solutions to public policy challenges to help make communities throughout the world safer and more secure, healthier and more prosperous. RAND is nonprofit, nonpartisan, and committed to the public interest.

RAND's publications do not necessarily reflect the opinions of its research clients and sponsors. RAND ${ }^{\circledR}$ is a registered trademark.

For more information on this publication, visit www.rand.org/t/PE152.

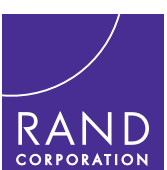

www.rand.org 